\title{
Enhanced Synaptic Transmission in the Extended Amygdala and Altered Excitability in an Extended Amygdala to Brainstem Circuit in a Dravet Syndrome Mouse Model
}

\author{
Wen Wei Yan, ${ }^{1, *}$ Maya Xia, ${ }^{1, *}$ Jeremy Chiang, ${ }^{1}$ Alyssa Levitt, ${ }^{1}$ Nicole Hawkins, ${ }^{2}$ Dennifer Kearney, ${ }^{2}$ \\ DGeoffrey T. Swanson, ${ }^{2}$ Dane Chetkovich, ${ }^{1}$ and William P. Nobis ${ }^{1}$
}

https://doi.org/10.1523/ENEURO.0306-20.2021

${ }^{1}$ Department of Neurology, Vanderbilt University Medical Center, Nashville, Tennessee 37232 and ${ }^{2}$ Department of Pharmacology, Northwestern University Feinberg School of Medicine, Chicago, Illinois 60611

\section{Visual Abstract}

A

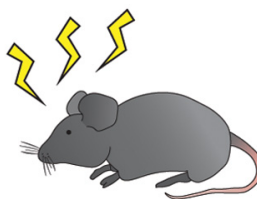

Spontaneous seizures

in Scn1a ${ }^{+/-}$(Dravet

Syndrome) mouse

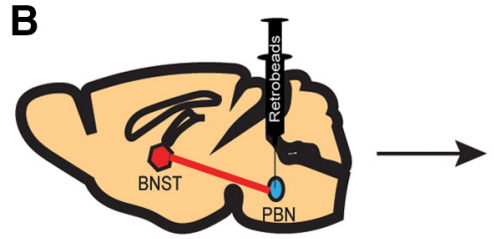

Decreased excitability

in BNST-brainstem

projection neurons

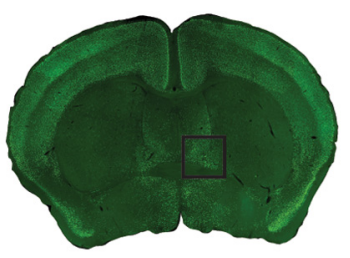

C-fos activation in bed nucleus of stria terminalis (BNST)

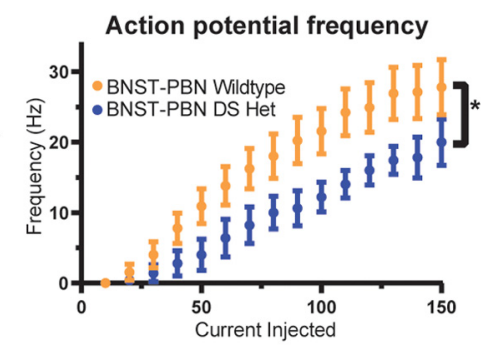

\section{Significance Statement}

Dravet syndrome (DS) is a developmental and epileptic encephalopathy with an increased risk of sudden death. We determined that there are alterations in a subcortical nucleus, the bed nucleus of the stria terminalis (BNST) of the extended amygdala, in a murine DS model. The BNST is involved in stress, anxiety, feeding, and respiratory function. We found enhanced activation in the BNST after seizures and alterations in basal synaptic neurotransmission, with enhanced spontaneous EPSC and decreased spontaneous IPSC events. Evaluating those neurons that project to the parabrachial nucleus, a nucleus with multiple homeostatic roles, we found them to be hypoexcitable in DS. Alterations in BNST to brainstem projections could be implicated in comorbid aspects of DS, including respiratory dysfunction and sudden death. 
Dravet syndrome (DS) is a developmental and epileptic encephalopathy with an increased incidence of sudden death. Evidence of interictal breathing deficits in DS suggests that alterations in subcortical projections to brainstem nuclei may exist, which might be driving comorbidities in DS. The aim of this study was to determine whether a subcortical structure, the bed nucleus of the stria terminalis (BNST) in the extended amygdala, is activated by seizures, exhibits changes in excitability, and expresses any alterations in neurons projecting to a brainstem nucleus associated with respiration, stress response, and homeostasis. Experiments were conducted using $\mathrm{F} 1$ mice generated by breeding $129 . \mathrm{Scn} 1 \mathrm{a}^{+/-}$mice with wild-type C57BL/6J mice. Immunohistochemistry was performed to quantify neuronal c-fos activation in DS mice after observed spontaneous seizures. Whole-cell patch-clamp and current-clamp electrophysiology recordings were conducted to evaluate changes in intrinsic and synaptic excitability in the BNST. Spontaneous seizures in DS mice significantly enhanced neuronal c-fos expression in the BNST. Further, the BNST had altered AMPA/NMDA postsynaptic receptor composition and showed changes in spontaneous neurotransmission, with greater excitation and decreased inhibition. BNST to parabrachial nucleus (PBN) projection neurons exhibited intrinsic excitability in wild-type mice, while these projection neurons were hypoexcitable in DS mice. The findings suggest that there is altered excitability in neurons of the BNST, including BNST-to-PBN projection neurons, in DS mice. These alterations could potentially be driving comorbid aspects of DS outside of seizures, including respiratory dysfunction and sudden death.

Key words: bed nucleus of the stria terminalis; Dravet syndrome; excitability; extended amygdala; parabrachial nucleus

\section{Introduction}

Dravet syndrome (DS) is a developmental and epileptic encephalopathy with multiple neuropsychiatric comorbidities and an increased risk of sudden death (Gataullina and Dulac, 2017). Most cases arise because of a de novo variant in the scn1a gene, encoding the sodium channel $\alpha$ subunit $\mathrm{Na}_{\mathrm{v}} 1.1$. Seizures, while usually present early and often being refractory, are not the only manifestation of the disease. Other common comorbidities can be just as impactful on patients and caregivers and include psychomotor delay, cognitive disability, mood disorders, dysautonomia, nutritional issues, and a significant risk of sudden unexpected death in epilepsy (SUDEP; Villas et al., 2017).

Murine models of DS recapitulate many aspects of human disease including severe epilepsy, cognitive and social deficits, and sudden death (Kalume et al., 2013; Lopez-Santiago and Isom, 2019). Work using these

\footnotetext{
Received July 8, 2020; accepted May 11, 2021; First published May 27, 2021.

The authors declare no competing financial interests.

Author contributions: W.W.Y., M.X., J.K., G.T.S., D.C., and W.P.N. designed research; W.W.Y., M.X., J.C., A.L., N.H., and W.P.N. performed research; N.H., J.K., and G.T.S. contributed unpublished reagents/analytic tools; W.W.Y., M.X., J.C., A.L., and W.P.N. analyzed data; M.X. and W.P.N. wrote the paper.

This work was supported by grants to W.P.N. from the American Epilepsy Society (Junior Investigator Award), a pilot grant from the National Institute for Neurologic Disease and Stroke Center for sudden unexpected death in epilepsy (SUDEP) center for SUDEP research (CSR), and the Vanderbilt Faculty Research Scholars (VFRS) award.

${ }^{*}$ W.W.Y. and M.X. contributed equally to this work

Acknowledgements: We thank Ye Han and Isabelle Reinteria for technical assistance and support.

Correspondence should be addressed to William P. Nobis at william. p.nobis@vumc.org.

https://doi.org/10.1523/ENEURO.0306-20.2021

Copyright @ 2021 Yan et al.
}

This is an open-access article distributed under the terms of the Creative Commons Attribution 4.0 International license, which permits unrestricted use, distribution and reproduction in any medium provided that the original work is properly attributed. models has begun to unravel the neurophysiological alterations in DS that may be underpinnings of these comorbidities. Cardiac abnormalities and peri-ictal breathing issues have been noted in patients and murine models, with more recent work implicating respiratory decline in SUDEP in DS mice. While a major hypothesis proposes that spreading depolarization and subsequent brainstem depression may trigger respiratory decline (Bernard, 2015); evidence of interictal breathing deficits in DS patients and mice suggests that direct alterations in brainstem respiratory centers or their subcortical projecting neurons may exist (Kim et al., 2018). Indeed, recent work shows altered excitability in a region critical for respiratory control and chemosensation (Kuo et al., 2019). It is also possible, yet largely unexplored, that alterations in subcortical projections to these brainstem nuclei may cause deficits as well, with potential far-reaching consequences that could contribute to comorbidities such as temperature dysregulation, mood disorders, feeding, cardiac and respiratory dysfunction, and risk for sudden death. Such alterations may be intrinsic to the subcortical structure or driven by seizures and upstream hyperexcitability.

Despite impressive study of DS mouse models and epilepsy, the neuronal basis for seizures in DS is still debated (Isom, 2014); however, it appears to critically involve forebrain disinhibition (Cheah et al., 2012; Favero et al., 2018; Yuan et al., 2019). Multiple electrophysiological studies demonstrate impaired firing of inhibitory neurons, and selective deletion of Scn1a in inhibitory neurons alone is sufficient to cause seizures and premature death (Cheah et al., 2012). Clearly, intrinsic deficits in cortical inhibition are driving hyperexcitability; however, little work has been performed on the electrophysiological changes in downstream subcortical targets (Derera et al., 2017; Kuo et al., 2019).

A recent study found that targeting a subcortical structure in DS mice, a nucleus of the extended amygdala, could have a significant effect on seizure-induced apneas 


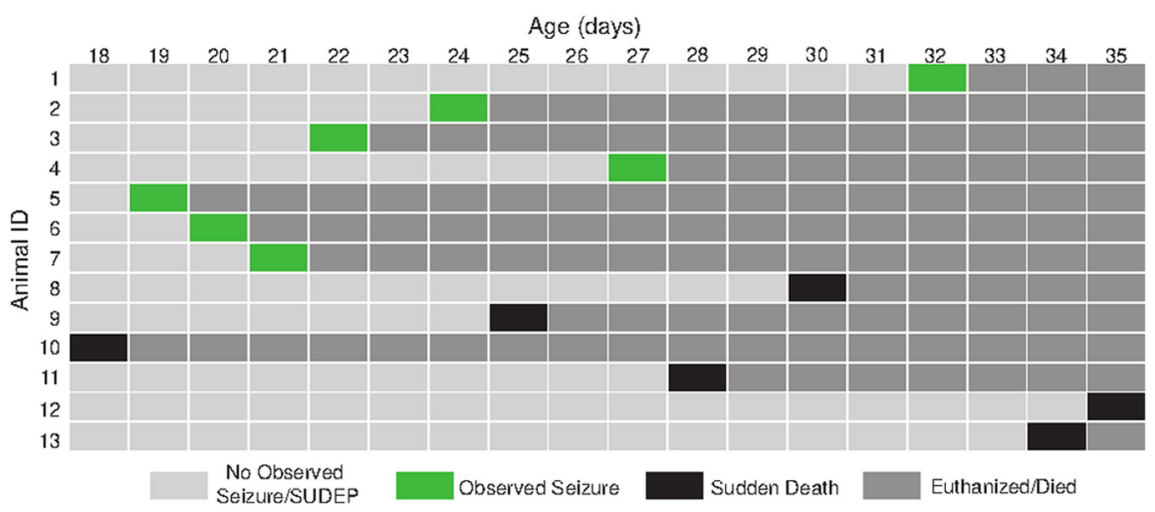

Figure 1. Seizures and sudden deaths captured from 18 to $35 \mathrm{~d}$ of age in DS mice. Light gray, No seizures or sudden deaths captured; green, observed spontaneous seizure in home cage, mice killed after capturing a seizure to stain for c-fos expression in the BNST; black, sudden death resulting in death of mouse; dark gray, mouse killed or died from SUDEP. Fifteen DS mice were monitored with a sudden death rate of $40 \%$.

and mortality because of SUDEP (Bravo et al., 2020). This important study suggests that alterations in a subcortical circuit may be driving an important aspect of DS respiratory dysfunction during seizures. In the present study, we aimed to determine whether another nucleus of the extended amygdala, the bed nucleus of the stria terminalis (BNST), is activated by seizures in DS animals, whether there exists any synaptic or intrinsic excitability changes in this nucleus, and whether neurons projecting to a brainstem structure important for both respiratory function and also overall homeostasis is altered, which could have implications for mechanisms and treatment of important comorbidities in DS.

\section{Materials and Methods}

\section{Mouse husbandry and genotyping}

Animal care and experimental procedures were approved in accordance with the National Institutes of Health Guide for the Care and Use of Laboratory Animals. Mice were group housed in a mouse facility under standard laboratory conditions (14/10 h light/dark cycle) and had access to food and water ad libitum.

Scn1 $\mathrm{a}^{\mathrm{tm} 1 \mathrm{Kea}}$ mice were obtained (Miller et al., 2014). The line has been maintained as a coisogenic strain by continuous backcrossing of null heterozygotes to 129 $\left(129 . S c n 1 a^{+/-}\right.$). 129S6/SvEvTac mice (stock \#129SVE) were obtained from Taconic. For experiments, F1 mice were produced by breeding heterozygous $129 . S \mathrm{cn} 1 \mathrm{a}^{+/-}$ mice with wild-type (WT) C57BL/6J mice (stock \#000664, The Jackson Laboratory). Mice were ear tagged and tail biopsied between postnatal day 14 (P14) and P20. At $\sim P 21, F 1$ mice were weaned into holding cages containing four to five mice of the same sex and age for experiments.

\section{Monitoring of spontaneous seizure activity and sudden death}

Animals were genotyped and ear tagged from $\mathrm{P} 14$ to P20. During this time, mice were also brought to an isolated room in the laboratory for handling each day to acclimate. Mice were kept in their home cage with ad libitum access to food and water during the daylight cycle. From P19 to P35, mice were monitored for tonic-clonic convulsive seizures in DS animals. After a DS mouse survived an observed seizure, the DS animal that had the seizure, and a DS littermate and a wild-type littermate, both of which did not have any observed seizures, were killed. Because c-fos expression peaks 1-2 $\mathrm{h}$ after stimulus onset (Hsieh and Watanabe, 2000), animals were killed 90 min after the experimenter witnessed a seizure, and their ages were recorded.

Animals were also monitored for sudden death. DS mice that died in their home cages in the mouse facility were marked as having experienced sudden death, and their ages of death were recorded (Fig. 1).

\section{c-fos fluorescent immunohistochemistry}

Mice were deeply anesthetized with isoflurane and transcardially perfused with ice-cold PBS followed by $4 \%$ paraformaldehyde (PFA). Brains were removed and postfixed for $48 \mathrm{~h}$ at $4^{\circ} \mathrm{C}$. Coronal sections $(30 \mu \mathrm{m})$ were made using a vibratome (Leica Biosystems). Antigen retrieval was performed with $10 \mathrm{~mm}$ sodium citrate, $\mathrm{pH}$ 6.0, for $20 \mathrm{~min}$ at $80^{\circ} \mathrm{C}$. Slices were cooled, washed with PBS, and immersed in blocking solution ( $5 \%$ normal goat serum, $0.65 \% \mathrm{w} / \mathrm{v}$ BSA, and $0.3 \%$ Triton $\mathrm{X}-100$ in PBS) for $1 \mathrm{~h}$ at room temperature with gentle agitation. The primary antibody (c-fos; Abcam) was diluted in blocking solution and applied overnight at $4^{\circ} \mathrm{C}$. Sections were then washed three times for 5 min each and incubated with fluorescently labeled secondary antibodies (Thermo Fisher Scientific) in blocking solution for $1 \mathrm{~h}$ at room temperature. Sections were washed an additional three times, with DAPI included in the final wash. Tissues were mounted on glass slides using PermaFluor (Thermo Fisher Scientific). Images were acquired on a microscopy camera (model DFC290, Leica Biosytems). The same acquisition parameters and alterations to brightness and contrast in ImageJ were used across all images within an experiment. Images were thresholded using the striatum image for each genotype as a negative control. Following 
thresholding, positive cells within the BNST were manually counted using ImageJ by a blinded reviewer. All numbers are reported as a single averaged value for each dorsal BNST (dBNST) and then averaged for each animal.

\section{Acute slice preparation}

Acute brain slices were prepared from P19 to P30 heterozygous and wild-type littermates of either gender, in accordance with Institutional Animal Care and Use Committee-approved protocols. Mice were decapitated under isoflurane, and their brains were removed quickly and placed in an ice-cold sucrose-rich slicing ACSF containing $85 \mathrm{~mm} \mathrm{NaCl}, 2.5 \mathrm{~mm} \mathrm{KCl}, 1.25 \mathrm{~mm} \mathrm{NaH}_{2} \mathrm{PO}_{4}, 25$ $\mathrm{mm} \mathrm{NaHCO}_{3}, 75 \mathrm{~mm}$ sucrose, $25 \mathrm{~mm}$ glucose, $10 \mathrm{~m} \mathrm{DL}-$ APV, $100 \mu \mathrm{m}$ kynurenate, $0.5 \mathrm{~mm} \mathrm{Na}$ L-ascorbate, $0.5 \mathrm{~mm}$ $\mathrm{CaCl}_{2}$, and $4 \mathrm{~mm} \mathrm{MgCl}_{2}$. Sucrose-ACSF was oxygenated and equilibrated with $95 \% \mathrm{O}_{2} / 5 \% \mathrm{CO}_{2}$. Hemisected coronal slices $(300 \mu \mathrm{m})$ were prepared using a vibratome (model VT1200S, Leica Biosystems). Slices were transferred to a holding chamber containing sucrose-ACSF warmed to $30^{\circ} \mathrm{C}$ and slowly returned to room temperature over the course of 15-30 min. Slices were then transferred to oxygenated ACSF at room temperature containing 125 $\mathrm{mm} \mathrm{NaCl}, 2.4 \mathrm{~mm} \mathrm{KCl,} 1.2 \mathrm{~mm} \mathrm{NaH}_{2} \mathrm{PO}_{4}, 25 \mathrm{~mm} \mathrm{NaHCO}_{3}$, $25 \mathrm{~mm}$ glucose, $2 \mathrm{~mm} \mathrm{CaCl}_{2}$, and $1 \mathrm{~mm} \mathrm{MgCl}_{2}$, and were maintained under these incubation conditions until recording.

\section{Electrophysiological recordings}

Slices were transferred to a submerged recording chamber continuously perfused at $2.0 \mathrm{ml} / \mathrm{min}$ with oxygenated ACSF maintained at $30 \pm 2^{\circ} \mathrm{C}$. Neurons in the dBNST were identified using infrared differential interference contrast on a microscope (Slicescope II, Scientifica). Whole-cell patch-clamp recordings were performed using borosilicate glass micropipettes with tip resistance between 3 and $6 \mathrm{M} \Omega$. Signals were acquired using an amplifier (Axon Multiclamp 700B, Molecular Devices). Data were sampled at $10 \mathrm{kHz}$ and low-pass filtered at $3 \mathrm{kHz}$. Access resistances ranged between 5 and $24 \mathrm{M} \Omega$ and were continuously monitored. Changes $>20 \%$ from the initial value were excluded from data analyses. Series resistance was uncompensated. Data were recorded and analyzed using pClamp 11 (Molecular Devices).

Current clamp was performed using a potassium gluconate-based intracellular solution containing the following (in mM): $135 \mathrm{~K}$-gluconate, $5 \mathrm{NaCl}, 2 \mathrm{MgCl}_{2}, 10 \mathrm{HEPES}, 0.6$ EGTA, $4 \mathrm{Na}_{2}$ ATP, and $0.4 \mathrm{Na}_{2} \mathrm{GTP}, \mathrm{pH} 7.3$, at 285-290 mOsm). Input resistance was measured immediately after breaking into the cell and was determined from the peak voltage response to a $-5 \mathrm{pA}$ current injection. Following stabilization and measurement of the resting membrane potential, current was injected to hold all cells at a membrane potential of $-65 \mathrm{mV}$, maintaining a common membrane potential to account for intercell variability. Changes in excitability were evaluated by measuring action potential (AP) dynamics and the number of action potentials fired at increasing $10 \mathrm{pA}$ current steps (-150 to $150 \mathrm{pA})$. The action potential threshold and the amount of current required to fire an action potential (rheobase) were assessed through a ramp protocol of $120 \mathrm{pA} / 1 \mathrm{~s}$. Parameters related to AP shape, which included AP height, AP duration at half-maximal height (AP half-width), and time to fire an AP (AP latency), were calculated from the first action potential fired during the $I-V$ plot. Hyperpolarization sag was calculated as the difference between the initial maximal negative membrane potential and the steady-state current after negative current injection. Neuron types were determined based on the classifications of Hammack et al. (2007) and Rodríguez-Sierra et al. (2013).

For the assessment of spontaneous activity, a cesium methanesulfonate-based intracellular solution (in mM: 135 Cs-methanesulfonate, $10 \mathrm{KCl}, 1 \mathrm{MgCl}_{2}, 0.2$ EGTA, 4 MgATP, $0.3 \mathrm{Na}_{2} \mathrm{GTP}, 20$ phosphocreatine, and $10 \mathrm{QX}-$ 314 , pH 7.3, at 285-290 mOsm) was used. Cells were voltage clamped at $-65 \mathrm{mV}$ to monitor spontaneous excitatory postsynaptic currents (sEPSCs) and held at $+10 \mathrm{mV}$ to isolate spontaneous inhibitory postsynaptic currents (sIPSCs). sIPSCs were measured in $120 \mathrm{~s}$ blocks, excluding $<5 \mathrm{pA}$ events. Analysis was performed using MiniAnalysis (Synaptosoft).

For evoked experiments, postsynaptic currents were evoked by electrical stimulation using a monopolar glass electrode placed dorsal to the recorded neuron controlled by a SIU91 constant current isolator (Cygnus Tech). An internal recording solution (in mm: $95 \mathrm{CsF}, 25 \mathrm{CsCl}, 10 \mathrm{Cs}-$ HEPES, 10 Cs-EGTA, 2 NaCl, 2 Mg-ATP, 10 QX-314, 5 TEA-Cl, and 5 4-aminopyridine, $\mathrm{pH} 7.3$, at 285-292 $\mathrm{mOSm}$ ) was used. To evaluate evoked EPSCs, picrotoxin (25 $\mu \mathrm{M})$ was added to the ACSF to block both synaptic and extrasynaptic $\mathrm{GABA}_{\mathrm{A}}$ receptors to assess postsynaptic glutamate transmission. To assess putative changes in presynaptic release probability, paired-pulse ratio (PPR; amplitude of EPSC2/EPSC1) was recorded at a $50 \mathrm{~ms}$ interstimulus interval, while the cells were voltage clamped at $-65 \mathrm{mV}$. Similar experiments were conducted to assess short-term plasticity at GABAergic terminals in the presence of kynurenic acid ( $3 \mathrm{~mm}$ ) to block ionotropic glutamate receptors. Since evoked IPSCs (eIPSCs) have slower kinetics, a $150 \mathrm{~ms}$ interstimulus interval was used and PPR was calculated as the delta amplitude of IPSC2 divided by the amplitude of IPSC1. NMDA/AMPA ratios were calculated based on the peak AMPAR-mediated EPSC amplitude measured at $-70 \mathrm{mV}$, and the NMDARmediated EPSC component measured at $40 \mathrm{~ms}$ following electrical stimulation at a $40 \mathrm{mV}$ holding potential, respectively. The reversal potential for NMDA receptors is near $0 \mathrm{mV}$ (Misra et al., 2000; Wyeth et al., 2014), and it has been previously determined that at this time point the AMPA component of the ESPC has completely decayed (Fernandes et al., 2009; Hedrick et al., 2017).

\section{RNAscope in situ hybridization}

RNAscope detection kits and cDNA probes were purchased from Advanced Cell Diagnostics (ACD) and were used to visualize mRNA species. All probes were generated against Mus musculus-specific transcripts and included parvalbumin (PV; catalog \#429131, ACD; channel 
1 probe, Mm-Pvalb target region 2-885; GenBank accession \#NM_013645.3) and Scn1a (556181, channel 2, MmScn1a target region 1028-4591; GenBank accession \#NM_001313997.1).

Wild-type and DS littermates were killed via an overdose of isoflurane, and brains were immediately extracted into optimal cutting temperature media, and brains were frozen with cryospray. Brains were stored at $-80^{\circ} \mathrm{C}$ overnight, then cut on a cryostat (model VT 1000S, Leica) at $16 \mu \mathrm{m}$. Sections were adhered to warm Fisher Plus slides (Thermo Fisher Scientific) and were immediately refrozen in dry ice. Slides were stored at $-80^{\circ} \mathrm{C}$ and fixed with icecold 4\% PFA for $15 \mathrm{~min}$ according to ACD protocol. Slides were then placed in an ethanol dilution series $(50 \%, 70 \%, 100 \% \times 2)$ for dehydration. Slides were air dried for $5 \mathrm{~min}$, and an ImmEdge Barrier Pen was used to draw a hydrophobic barrier around each section. The ACD four-solution pretreatment was used to incubate sections for $30 \mathrm{~min}$ at room temperature in a water bath. Sections were then incubated with RNAscope probes, and the amplification steps were carried out in accordance with the ACD protocol for the Fluorescent Multiplex Kit. Incubation steps included the following: probe mixtures in the kit recommended dilutions for the $\mathrm{C} 1$ channel (parvalbumin mRNA) and the C2 channel (Scn1a mRNA) for $2 \mathrm{~h}$ at $40^{\circ} \mathrm{C}$, wash $\times 2$, AMP- $1 \mathrm{FL}$ reagent for $30 \mathrm{~min}$ at $40^{\circ} \mathrm{C}$, wash $\times 2$, AMP-2 $\mathrm{FL}$ reagent for $15 \mathrm{~min}$ at $40^{\circ} \mathrm{C}$, wash $\times 2$, AMP-3 FL reagent for $30 \mathrm{~min}$ at $40^{\circ} \mathrm{C}$, wash $\times 2$, AMP-4 FL alt A or B reagent for $15 \mathrm{~min}$ at $40^{\circ} \mathrm{C}$, wash $\times 2$, DAPI reagent for 1-2 min at room temperature, remove standing liquid, mount, and immediately coverslip with Invitrogen SlowFade Gold (Thermo Fisher Scientific).

Images were acquired on a microscopy camera (model DFC290, Leica Biosytems) with a $20 \times$ objective. The same acquisition parameters and alterations to brightness and contrast in Image J were used across all images within an experiment. ImageJ software was used to manually count mRNA signals by a blinded reviewer. All numbers are reported as a single averaged value for each hippocampus and dBNST and then were averaged for each animal.

\section{Stereotaxic surgeries}

Mice were anesthetized with isoflurane (initial dose, $3 \%$; maintenance dose, $1.5 \%$ ) and injected intracranially with red Retrobeads (Lumafluor). A targeted microinjection of the Retrobeads (100 nl) was carried out into the lateral parabrachial nucleus (PBN; coordinates from bregma: medial/lateral, $\pm 1.4 \mathrm{~mm}$, anterior/posterior, $-4.9 \mathrm{~mm}$; dorsal/ventral, $3.8 \mathrm{~mm}$; Paxinos and Franklin, 2019). All injections were unilateral. Mice were treated with $5 \mathrm{mg} / \mathrm{kg}$ injections of ketoprofen for $48 \mathrm{~h}$ following surgery. Electrophysiological recordings were made from these injected animals $48-72 \mathrm{~h}$ after injection.

\section{Experimental design and statistical analysis}

The number of animals used and the number of cells evaluated are noted in the Results section for each experiment. Animals of either sex were used during this study, and potential sex-specific differences were evaluated. We did not assume a Gaussian distribution; as such, all comparisons are nonparametric unpaired $t$ tests (Mann-Whitney $U$ test) used to determine statistical significance. Mean \pm SEM values are provided throughout the text. Scatter plots are shown for all data, with mean and SEM graphically depicted. Outliers were removed if values were outside the $95 \%$ confidence interval, and it is noted in the text when outliers were removed.

\section{Results}

\section{Spontaneous seizures induce c-fos expression in the dBNST in DS mice}

We first wanted to determine whether the BNST was activated by seizures in DS mice. To do this, we analyzed expression patterns of the immediate early gene c-fos following seizures in the dBNST. Previous studies consistently show robust c-fos expression in hippocampal regions following seizures; however, nuclei of the extended amygdala have not yet been evaluated (Dutton et al., 2017; Huffman et al., 2018). We monitored naive Scn1a ${ }^{+/-}$mice for spontaneous seizures in their home cage with wild-type littermates from P19 to P35 (Fig. 2A). None of the wild-type littermates experienced a seizure. Following a spontaneous seizure, there was a significant increase in c-fos-positive cells in the dBNST compared with wild-type littermates and DS littermates that did not have an observed seizure (DS seizure: $987 \pm 186.1$ cells/ $\mathrm{mm}^{2}, n=7$; DS no seizure: $231.6 \pm 64.59 \mathrm{cells} / \mathrm{mm}^{2}$, $n=6$; WT: $134.4 \pm 50.14$ cells $/ \mathrm{mm}^{2}, n=7$; DS seizure vs WT: $p=0.0004$; DS seizure vs DS no seizure: $p=0.0021$; Fig. $2 B, C)$. There was no significant difference in c-fos activation at baseline levels in DS mice and WT mice (DS no seizure vs WT: $p=0.1263$; Fig. $2 B, C)$. In contrast, there was no significant increase in c-fos cells in the dorsal striatum in these animals, a region like the BNST that has stress responsiveness (Perrotti et al., 2004). This increased activation appears to result from seizures, as there was no difference in dBNST c-fos activation at baseline with just stress of handling (Fig. $2 B, C$ ).

\section{Altered postsynaptic receptor composition in the dBNST in DS mice without changes in release probability}

As an initial electrophysiological investigation into potential alterations in dBNST neurons in DS mice, we measured evoked synaptic properties (Fig. $3 A, B$ ). First, we evaluated synaptic facilitation, a form of short-term plasticity. We bath applied either $\mathrm{GABA}_{A}$ or ionotropic glutamate receptor blockers to isolate excitatory or inhibitory evoked events. We evoked pairs of postsynaptic currents by delivering electrical stimulation, allowing us to measure a PPR. PPR alterations reflect changes in the probability of presynaptic neurotransmitter release (Regehr, 2012). Such alterations are seen in the dentate gyrus in other DS mouse models (Tsai et al., 2015). We found no changes in excitatory PPR (WT: $1.38 \pm 0.09$, $n=9$ cells from 6 mice, DS: $1.39 \pm 0.9, n=11$ cells from 7 mice; $p>0.99$; Fig. $3 A$ ) or inhibitory PPR (WT: $0.92 \pm 0.08$, 
A
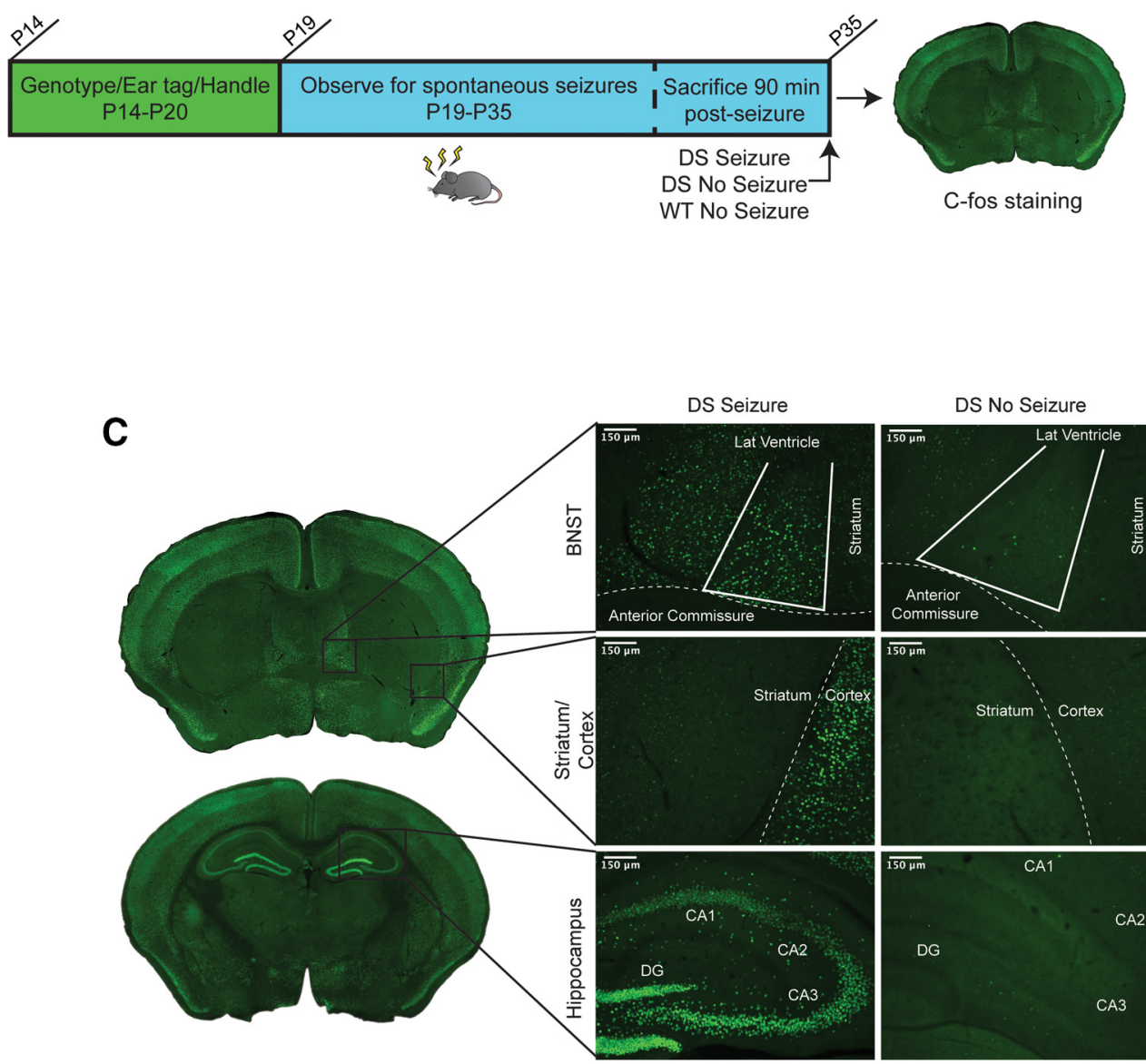

B

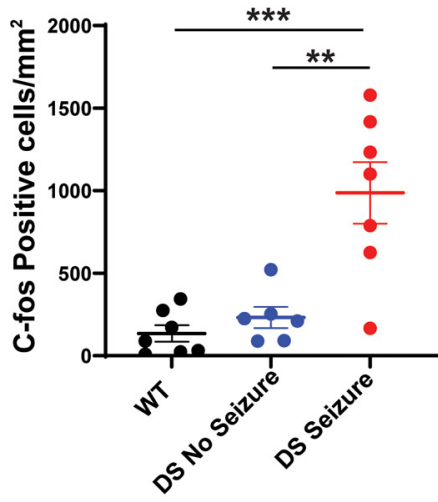

DS No Seizure

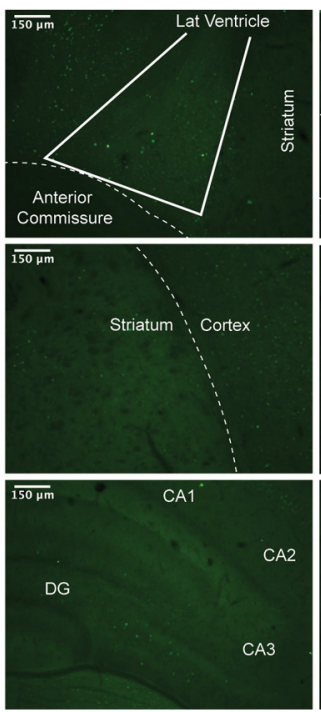

WT Littermate

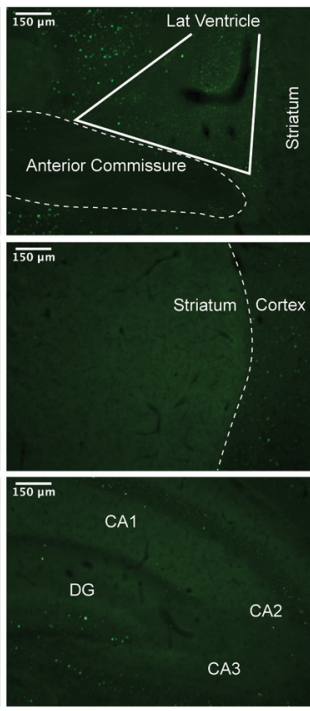

Figure 2. c-fos expression in dBNST increases after spontaneous seizures in DS mice. $\boldsymbol{A}$, Schematic showing timeline of homecage monitoring for seizures and immunohistochemistry for c-fos in dBNST of DS and WT littermates. $\boldsymbol{B}$, Scatter plot showing a significant increase in the mean number of c-fos-activated cells in dBNST sections of DS mice after a spontaneous seizure (DS seizure, $n=7$; DS no seizure, $n=6$; WT, $n=7$; DS seizure vs WT, $p=0.0004$; DS seizure vs DS no seizure, $p=0.0021$; DS no seizure vs WT, $p=0.1263)$. $\boldsymbol{C}$, Coronal sections denote dBNST, striatum, and hippocampus regions. Representative images of c-fos in DS mice 1.5 h postseizure, DS littermates with no seizure, and WT littermates with no seizure. Striatum served as a negative control and hippocampus as a positive control for c-fos expression. ${ }^{\star \star *} p<0.001,{ }^{\star *} p<0.01$.

$n=6$ cells from 5 mice; DS: $0.99 \pm 0.09, n=6$ cells from 5 mice; $p=0.59$; Fig. $3 B$ ) in the dBNST. We further investigated the contribution of postsynaptic receptors to these evoked excitatory currents. We measured AMPA receptor-mediated EPSCs by voltage clamping the cell at $-70 \mathrm{mV}$, and NMDA receptor-mediated currents by holding the same cell at $+40 \mathrm{mV}$. This allowed us to calculate the AMPA/NMDA ratio for each cell. Changes in AMPA/NMDA ratio are a potential hallmark for evidence of plasticity and are seen after learning and memory tasks, but also in pathologic situations such as temporal lobe epilepsy models (Amakhin et al., 2017). We found a significant increase in this ratio in DS mice in dBNST neurons (WT: $1.9 \pm 0.3, n=7$ cells from 5 mice; DS: $3.3 \pm 0.4$, $n=14$ cells from 8 mice; $p=0.04$; Fig. $3 C$ ).

\section{Decreased spontaneous inhibitory and enhanced excitatory neurotransmission in DS mice}

Excitatory and inhibitory (E-I) balance is altered in DS mice in cortical and hippocampal regions; to examine the effect of this on the dBNST, we measured both sEPSCs and sIPSCs. Using a Cs-methanesulfonate internal solution (see Materials and Methods), we could measure both sEPSCs when voltage clamped at $-65 \mathrm{mV}$ and spontaneous sIPSCs in the same cells when voltage clamped at $+10 \mathrm{mV}$ (Fig. 4A). While there were no changes in the frequency of excitatory events (WT: $3.7 \pm 1.9 \mathrm{~Hz}, n=15$ cells from 7 mice; DS: $3.9 \pm 0.5 \mathrm{~Hz}, n=15$ cells from 8 mice; $p=0.68$; Fig. $4 C$; all experiments in this section are from the same number of mice/cells), there was a significant increase in amplitude of spontaneous events (WT, $13.8 \pm 0.77 \mathrm{pA}$; DS, $17.7 \pm 1.25 \mathrm{pA} ; p=0.016$; Fig. $4 F, G$ ). This is consistent with the increase in AMPA/NMDA, which could result from either a decrease in NMDA synaptic currents or a selective increase in AMPA synaptic currents. Spontaneous inhibitory events in the dBNST were diminished, with a trend for a decrease in SIPSC frequency (WT: $4.8 \pm 0.9 \mathrm{~Hz}, n=14$ cells from 7 mice with one high outlier removed; DS: $2.8 \pm 0.4 \mathrm{~Hz} ; p=0.056$; Fig. 4C,E). 
A

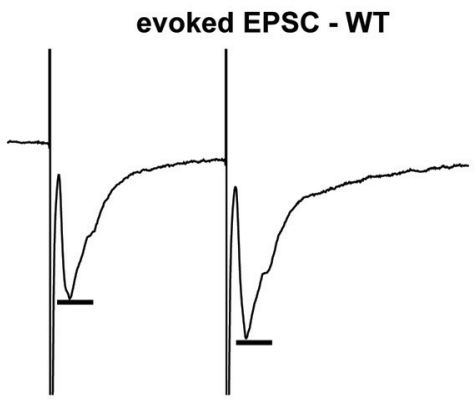

B evoked IPSC - WT evoked EPSC - DS

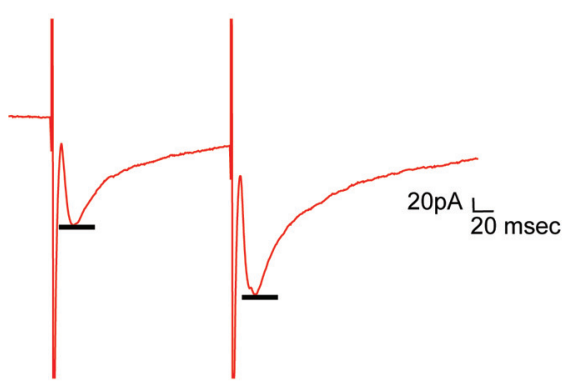

evoked IPSC - DS
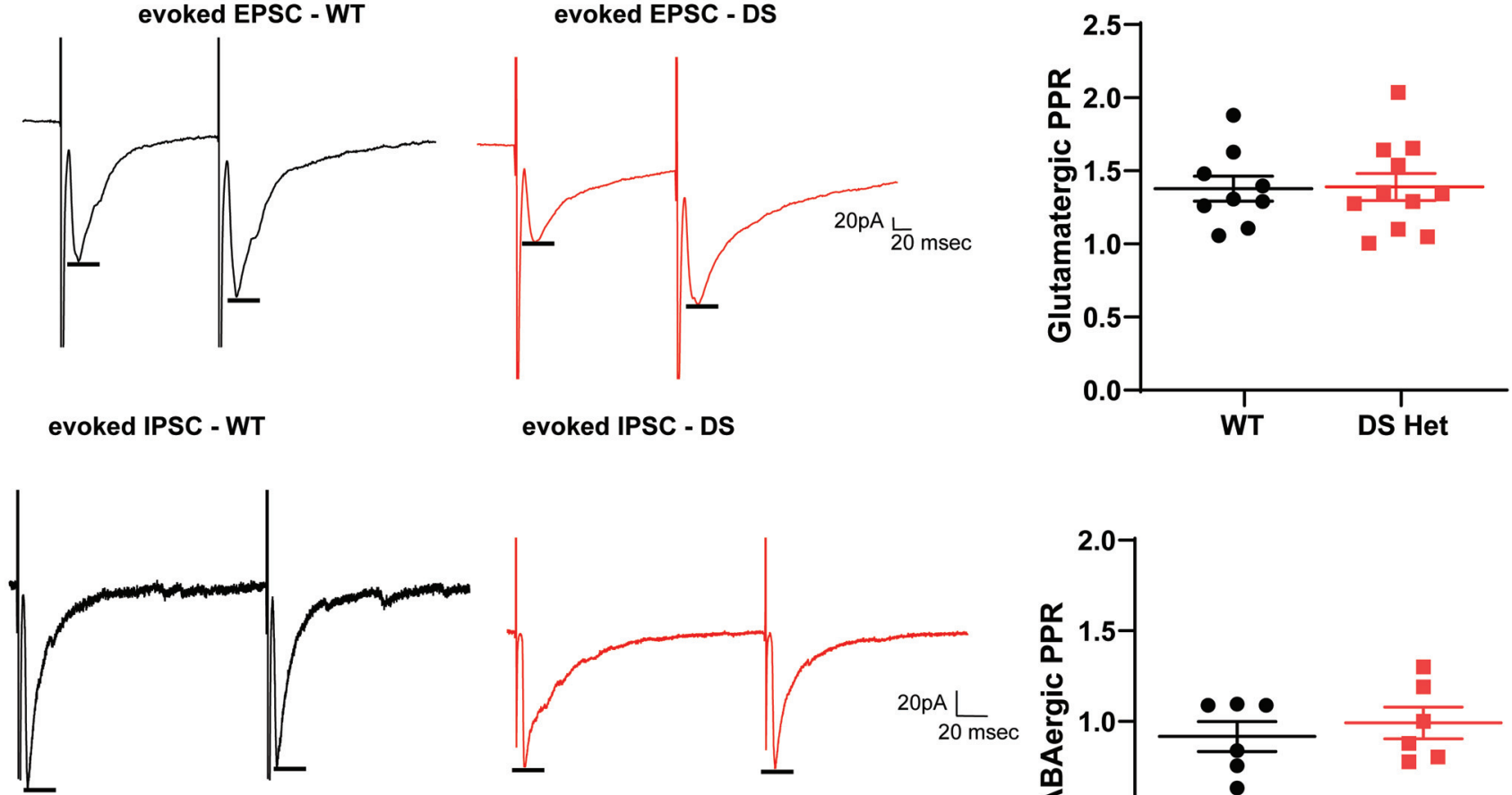

C

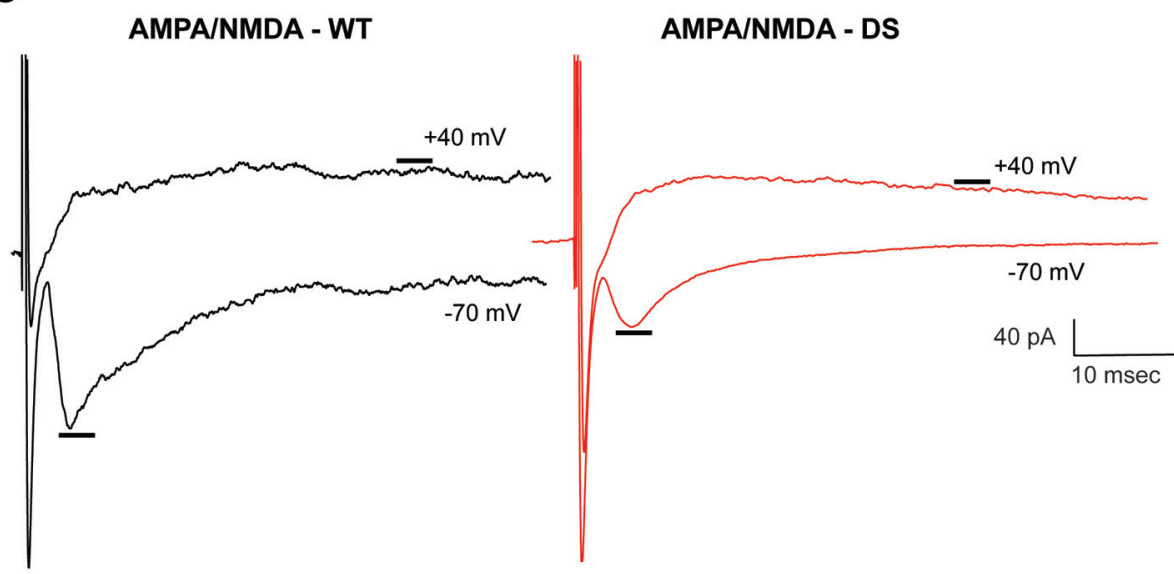

Figure 3. Postsynaptic receptor composition in dBNST is altered in DS mice, but there are no changes in release probability.

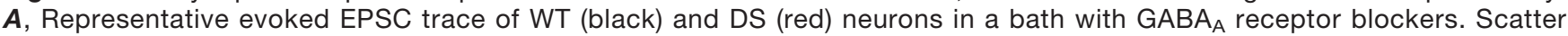
plot showing no significant change in excitatory paired-pulse ratios (WT, $n=9$; DS, $n=11 ; p>0.99$ ). $\boldsymbol{B}$, Representative elPSC trace of WT and DS neurons in a bath with ionotropic glutamate receptor blockers. Scatter plot showing no change in inhibitory paired pulse ratios (WT, $n=6$; DS, $n=6 ; p=0.59$ ). $\boldsymbol{C}$, Representative traces of AMPA receptor- and NMDA receptormediated EPSCs in WT and DS neurons. Scatter plot showing a significant increase in AMPA/NMDA ratio in DS mice (WT, $n=7 ; \mathrm{DS}, n=14 ; p=0.04)$. ${ }^{*} p<0.05$.

Given the heterogeneous nature of BNST inputs and intrinsic circuits, a decrease in the number of release sites could be driving this change (Li et al., 2012). There was also a trend for a decrease in the sIPSC amplitude in DS mice (WT, $23.5 \pm 2.1 \mathrm{pA}$; DS, $19.2 \pm$ $1.3 p A ; p=0.09$; Fig. $4 F, H)$. Using this approach to look at both sEPSC and sIPSC within neurons, we calculated an E-I balance for each, determining that there was a trend for an increase in DS mice in the frequency of excitatory to inhibitory PSCs (WT, $0.89 \pm$ 0.11 ; DS, $1.38 \pm 0.80 ; n=13$ from 7 mice with two high outliers removed; $p=0.059$; Fig. $4 B$ ). Overall, there is an increase in basal synaptic drive in the dBNST in DS mice. 
A

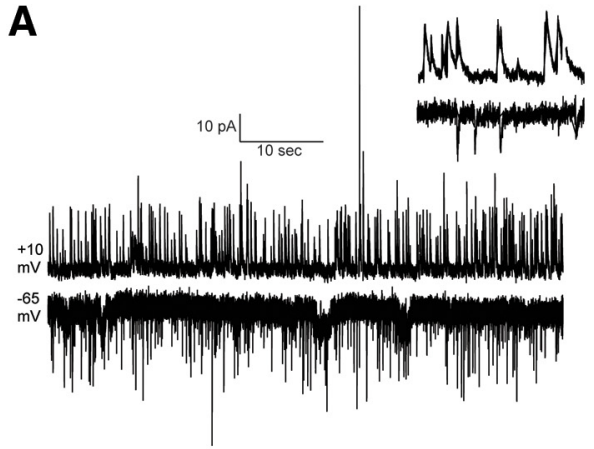

C

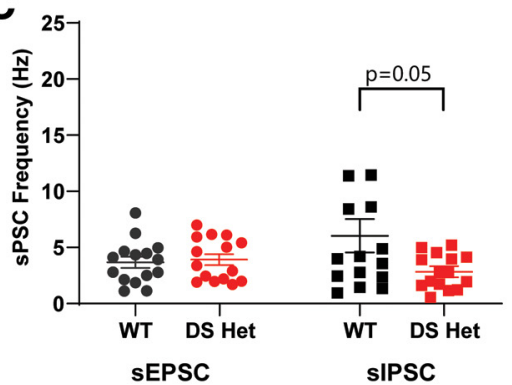

$\mathbf{F}$

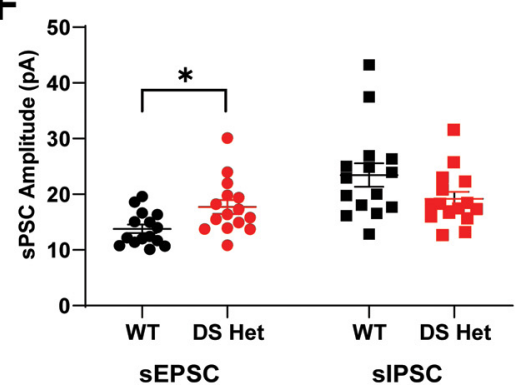

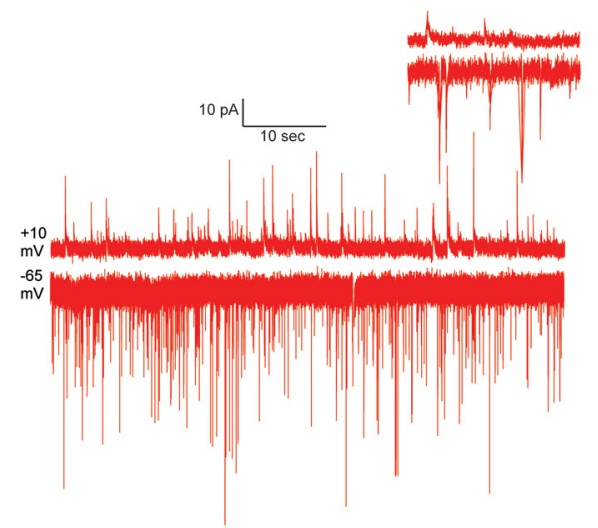

B

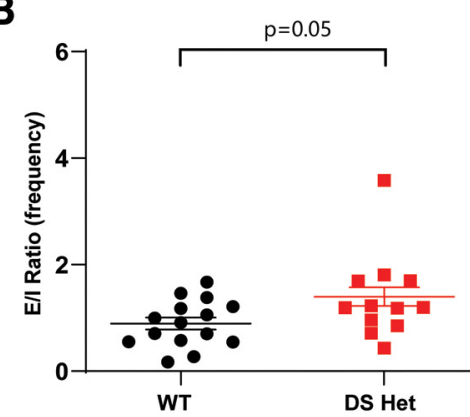

D

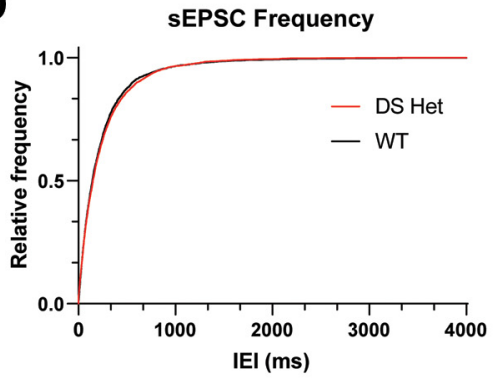

E

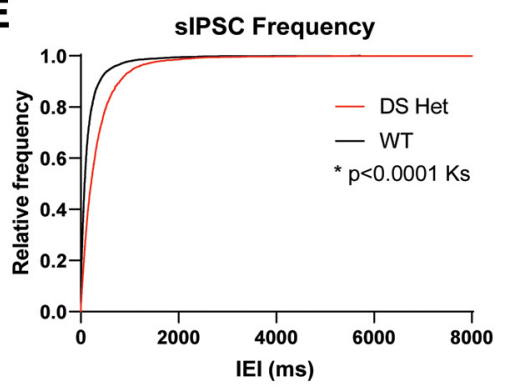

G

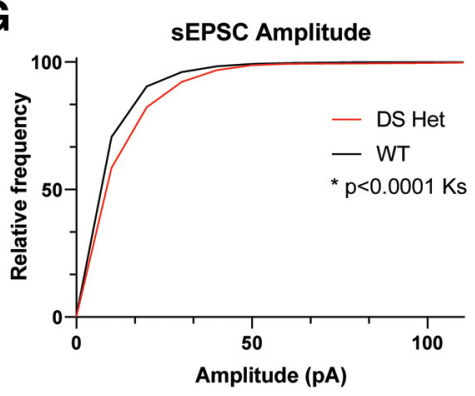

H

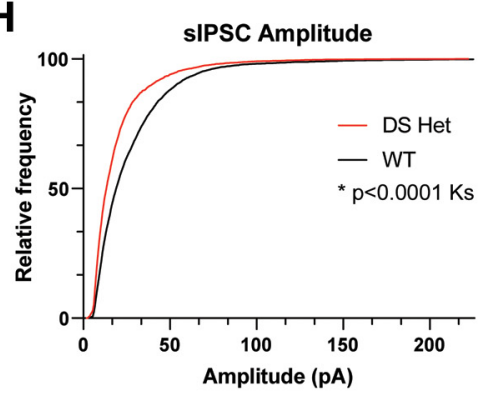

Figure 4. Spontaneous inhibitory neurotransmission is decreased in DS mice, while spontaneous excitatory neurotransmission is enhanced. $\boldsymbol{A}$, Example $60 \mathrm{~s}$ traces of WT (black) and DS (red) recordings of sIPSCs at $+10 \mathrm{mV}$ (top) and of sEPSCs at $-65 \mathrm{mV}$ (bottom). Inset, $2 \mathrm{~s}$ trace (top right). $\boldsymbol{B}$, Scatter plots showing significant increase in E/I ratio of the frequency of sEPSCs to sIPSCs in DS mice $(p=0.056)$. $C$, Scatter plots showing no significant change in sEPSC frequency (WT, $n=15 ; \mathrm{DS}, n=15 ; p=0.68)$ and a significant decrease in SIPSC frequency in DS mice $(p=0.046)$. $\boldsymbol{D}, \boldsymbol{E}$, Cumulative probability plots for sEPSC frequency showing no change, with sIPSC frequency showing a significant decrease in DS mice. $\boldsymbol{F}$, Scatter plots showing a significant increase in sEPSC amplitude $(p=0.016)$ and a decrease in SIPSC amplitude in DS mice $(p=0.059)$. $\boldsymbol{G}, \boldsymbol{H}$, Cumulative probability plots for sEPSC amplitude showing a significant increase, with sIPSC amplitude showing a significant decrease in DS. * $p<0.05$.

\section{Minor changes in overall intrinsic excitability of dBNST neurons in DS mice}

The $\mathrm{Na}_{\mathrm{V}} 1.1$ channel is a component of many inhibitory neurons, and its loss of function in DS models results in diminished excitability and altered AP dynamics. To investigate whether alterations exist in intrinsic excitability of the largely GABAergic population of both projection and interneurons in the dBNST, we first used brief voltage steps to measure intrinsic properties including input resistance (WT: $625 \pm 39.3 \mathrm{M} \Omega, n=18$ cells from 9 mice; DS: $666 \pm 75.3 \mathrm{M} \Omega, n=19$ cells from 8 mice; $p=0.96$; all experiments in this section are from the same number of mice/cells) and capacitance (WT, $49 \pm 4.0 \mathrm{pF}$; DS, $56 \pm 7.0 \mathrm{pF} ; p=0.62$ ) before assessing AP kinetics and excitability in current clamp. After recording the resting membrane potential (RMP; WT, $-60.5 \pm 0.56 \mathrm{mV}$; DS, $-60.7 \pm 0.73 \mathrm{mV} ; p=0.85$; Fig. $5 D$ ), all measurements were recorded in neurons clamped at $-65 \mathrm{mV}$ to account for the slight variabilities of RMPs between neurons. Overall, there was no change in the number of generated APs across the range of current injections (Fig. 5B), nor were there changes in the rheobase (minimum current required to elicit AP: WT, $57 \pm 4.2 \mathrm{pA}$; DS, $49 \pm 4.5 \mathrm{pA}$; $p=0.12$; Fig. $5 E$ ) between the groups. Similarly, AP latency, amplitude, and half-width were unchanged between groups (Fig. $5 H-J$ ). Notably, the threshold to fire the first AP was decreased in DS mice (WT, $-32.9 \pm$ $1.28 \mathrm{mV}$; DS, $-39.6 \pm 1.72 \mathrm{mV} ; p=0.007$; Fig. $5 F$ ), indicating 


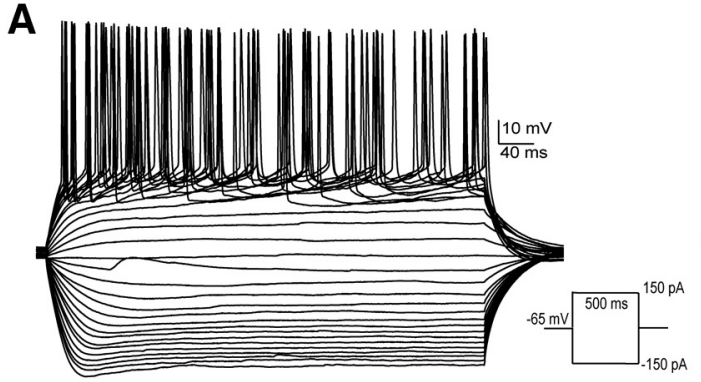

C

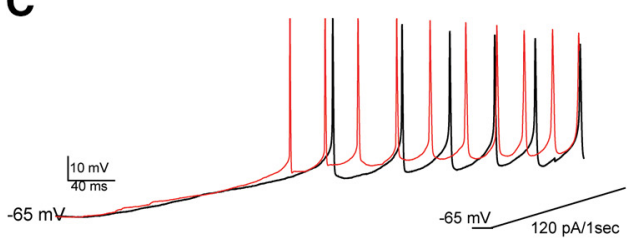

G

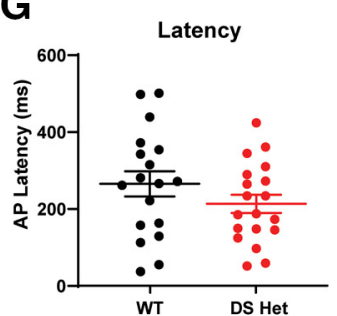

D

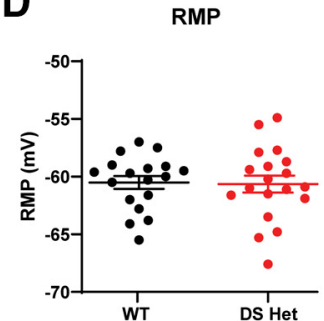

H

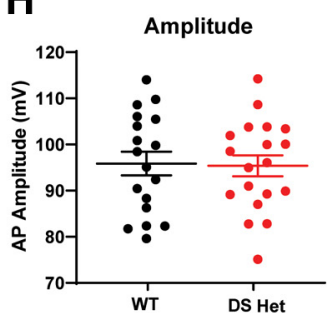

B

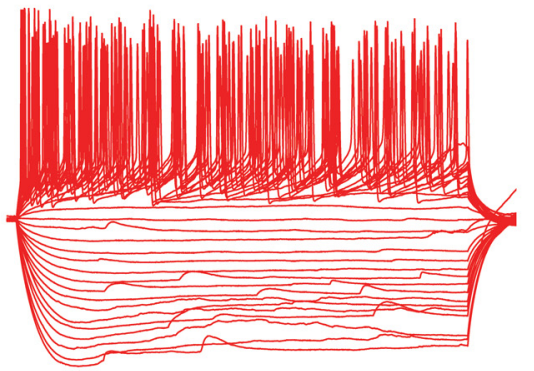

E

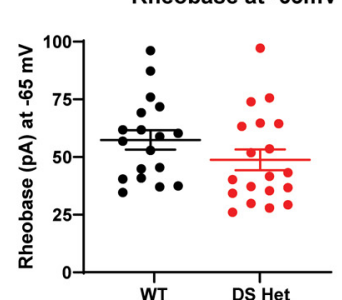

I

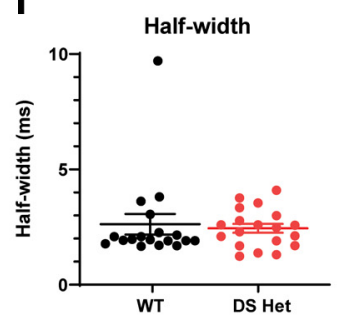

Actional Potential Frequency

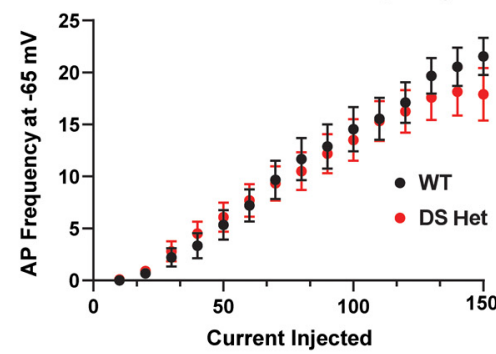

F Threshold at $-65 \mathrm{mv}$

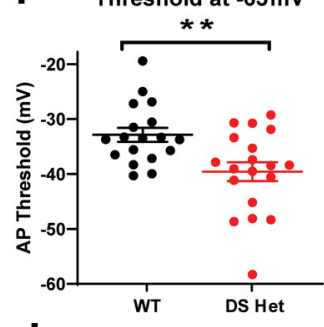

J

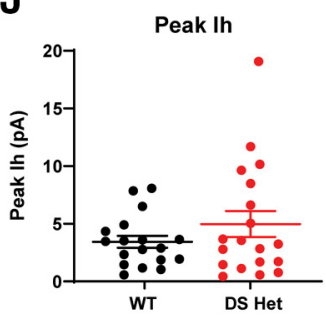

Figure 5. The overall intrinsic excitability of neurons is slightly enhanced in the dBNST of DS mice as a result of lower action potential threshold. $\boldsymbol{A}$, Representative traces of action potentials during current injection protocol in WT (black) and DS (red) mice. $\boldsymbol{B}$, Summary plot showing no difference in action potential frequency after current injection. $\boldsymbol{C}$, Representative trace of ramp current injection in WT (black) and DS (red) mice. $\boldsymbol{D}, \boldsymbol{E}$, Scatter plots showing no difference in resting membrane potential (WT, $n=18$; DS, $n=19 ; p=0.85)$ and rheobase $(p=0.12)$. $\boldsymbol{F}$, Scatter plot showing significantly lower action potential threshold in $\mathrm{DS}$ mice $(p=0.007)$. G-J, Scatter plots showing no changes in action potential latency, amplitude, half-width, and peak $I_{\mathrm{h}}$ in WT and DS mice. Scn1a expression in the BNST is unlikely to play a role in excitability changes, as we find low levels of both Scn1a and parvalbumin in WT and DS mice (Extended Data Figure 5-1). ${ }^{* *} p<0.01$.

the slight increase in excitability. The BNST is a heterogeneous population; however, the neurons can be divided based on their intrinsic membrane currents (Egli and Winder, 2003; Hammack et al., 2007). When subdividing into these categories (type I, type II, type III, and other), there were no differences in intrinsic excitability between the WT and DS groups, aside from type I neurons displaying a lower threshold (WT: $-32.6 \pm 1.56 \mathrm{mV}, n=8$ cells; DS: $-38.1 \pm 1.22 \mathrm{mV}, n=5$ cells; $p=0.02$ ). To determine whether excitability changes were influenced by loss of Nav1.1 channels in BNST neurons, we evaluated mRNA expression of Scn1a in the BNST using fluorescence in situ hybridization (RNAscope), finding low levels of Scn1a and parvalbumin in both WT and DS mice (Extended Data Fig. 5-1).

\section{dBNST neurons projecting to the PBN are a more excitable population than non-PBN-projecting neurons}

To determine how changes in the BNST may be influencing downstream targets driving DS comorbidities, we chose to focus on neurons that project to the PBN. The PBN is a brainstem structure involved in arousal, respiratory function, and overall homeostatic functions (Campos et al., 2018). To target these neurons, we stereotaxically injected red Retrobeads unilaterally into the PBN and performed whole-cell current-clamp experiments from both fluorescent and nonfluorescent neurons (Fig. 6A-C) 48$72 \mathrm{~h}$ after injection. These neurons on average had a higher input resistance (fluorescent: $662 \pm 71 \mathrm{M} \Omega, n=15$ cells from 11 mice; nonfluorescent: $490 \pm 33 \mathrm{M} \Omega, n=8$ cells from 8 mice; unpaired $t$ test, $p=0.058$; Fig. $6 H$; all experiments in this section are from the same number of mice/ cells) and a trend for a larger capacitance (fluorescent, $53 \pm 5.8 \mathrm{pF}$; nonfluorescent, $34 \pm 6.8 \mathrm{pF}$; unpaired $t$ test, $p=0.1$ ), consistent with BNST projection neurons (Luster et al., 2019). Furthermore, we found that dBNST neurons projecting to the PBN are more excitable-firing more APs across ranges of current injections (two-way ANOVA: $F_{(15,390)}=25.83 ; p<0.0001$ for main effect of group; Fig. $6 F$ ) and with a significantly lower rheobase (fluorescent, $47 \pm 1.7 \mathrm{pA}$; nonfluorescent, $65 \pm 5.7 \mathrm{pA}$; unpaired $t$ test, $p=0.0009$; Fig. $6 H$ ). Otherwise, there were no differences in RMP, AP kinetics, peak $I_{h}$, or threshold in these neurons 
in wild-type littermates. Previous reports indicate that neurons in the rat and mouse BNST can be categorized into at least three distinct neuronal subtypes based on voltage responses to transient current steps (Egli and Winder, 2003; Hammack et al., 2007). All of these physiologically distinct types of neurons were represented in the population of BNST neurons projecting to the PBN, suggesting that changes in excitability in these projection neurons are not simply an enrichment for one type. The plurality of these were type I neurons ( $n=6$ of 15 cells), but type II neurons ( $n=2$ of 15 cells), type III neurons ( $n=4$ of 15 cells), and other neurons ( $n=3$ of 15) are present. The fact that there is not a strict predominance of a single physiological type in those neurons projecting to the PBN is not unexpected as neuronal morphology, expression of neuropeptide markers, and projection location have not been shown previously to associate with a particular physiological subtype (Rodríguez-Sierra et al., 2013; Silberman et al., 2013; Ch'ng et al., 2019).

\section{dBNST neurons projecting to the PBN are hypoexcitable in DS mice}

To determine how these potentially important projection neurons were altered in DS mice, we similarly performed recordings from dBNST neurons in DS mice unilaterally injected with red Retrobeads in the PBN. Fluorescent neurons, representing those dBNST neurons projecting to the PBN, had a significantly hyperpolarized RMP in DS mice compared with fluorescent neurons in WT mice (fluorescent WT: $-61 \pm 1.0$ $\mathrm{mV}, n=15$ cells from 11 mice; nonfluorescent WT: $-60 \pm 0.82 \mathrm{mV}, n=8$ cells from 8 mice; fluorescent DS: $-65 \pm 1.2 \mathrm{mV}, n=8$ cells from 6 mice; nonfluorescent DS: $-63 \pm 1.0, n=8$ cells from 6 mice; $p=0.05$, Tukey's post hoc test; Fig. 6G; all experiments in this section are from the same number of mice/cells). Strikingly, dBNST-to-PBN projection neurons in DS mice no longer had an increase in AP fired with respect to current injections, suggesting that these brainstemprojecting neurons have decreased excitability in DS mice (two-way ANOVA and Tukey's post hoc test; fluorescent DS vs nonfluorescent WT, $p=0.21$; fluorescent DS vs nonfluorescent DS, $p=0.74$ for main effect of group; Fig. 6).

Other parameters, including AP amplitude, half-width, latency, and peak $I_{\mathrm{h}}$ were unchanged (Fig. 6/-K). In DS mice, dBNST projection neurons are therefore hypoexcitable (hyperpolarized, decreased AP firing) with normal AP kinetics.

\section{Discussion}

The current study was motivated by the relative paucity of investigation of subcortical structures in DS despite the impact that pathology in these regions may have on multiple aspects of DS, including sudden death. We used the

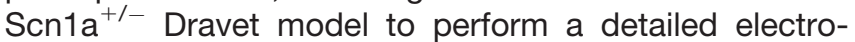
physiological examination of the dorsal BNST of the extended amygdala, as it receives inputs from cortical and hippocampal regions (Reichard et al., 2017) and has dense outputs to brainstem structures (Dong and
Swanson, 2006). This report shows that the dBNST is activated by seizures in DS mice and that there is marked excitatory-inhibitory synaptic imbalance in this region as well as alterations in postsynaptic receptor composition. We further investigated those BNST neurons projecting to the lateral $\mathrm{PBN}$ region in the pons and found that these neurons are a physiologically distinct population that are hypoexcitable in DS mice. These results provide evidence for distinct neuroadaptations in the BNST in DS mice and are complementary to the growing literature investigating the importance of subcortical structures in the Dravet model (Kuo et al., 2019; Bravo et al., 2020).

\section{Enhanced synaptic drive and synaptic strength in the BNST in DS mice}

We provide evidence of enhanced synaptic drive in the dorsal BNST in DS mice, with an increase in the amplitude of spontaneous excitatory events and a decrease in both the amplitude and frequency of inhibitory events. We additionally show evidence of postsynaptic changes, with an increase in AMPA/NMDA ratio, which suggests that alterations in postsynaptic glutamate receptors may be driving the increase in amplitude of sEPSCs. This may be driven by an enhanced excitatory drive from cortical pyramidal neurons and the ventral hippocampus, which have increased firing in DS mouse models (Yu et al., 2006; Mistry et al., 2014; Tai et al., 2014), and both project to the BNST. A decrease in inhibitory drive, both the amplitude and frequency of events, could be a counterbalancing effect for the enhanced excitatory drive. Alternatively, neuronal firing of inhibitory inputs could also be diminished. The BNST receives the majority of its inhibitory input from the central amygdala (CeA; Cassell et al., 1999), and, unlike the BNST, the CeA has a large population of PV neurons (Wang et al., 2016), which likely have impaired firing in DS mice (Yu et al., 2006; Tai et al., 2014). Finally, our data strongly suggest that the BNST is highly activated following seizures in DS mice. The frequency of seizures and subsequent strong neuronal activation of this region might be driving alterations in AMPA/NMDA ratio and producing compensatory changes in inhibitory synaptic drive.

\section{Subtle increase in intrinsic excitability in BNST neurons in DS mice}

We found subtle changes in intrinsic excitability overall, with an increase in the intrinsic excitability of dBNST neurons associated with a lowering of threshold to fire an AP. This was, however, not associated with any increase in spike frequency with current injections or other changes in excitability or AP kinetics. The somewhat contradictory nature of this is likely because of the heterogeneity of the BNST neurons and the inability to distinguish between interneurons or projection neurons when doing blind-patching experiments-there may be a population within the dBNST that has a more striking enhancement in intrinsic excitability if they were to be targeted directly. Many of the dBNST neurons are GABAergic, with both interneurons and inhibitory projection neurons. In other brain 


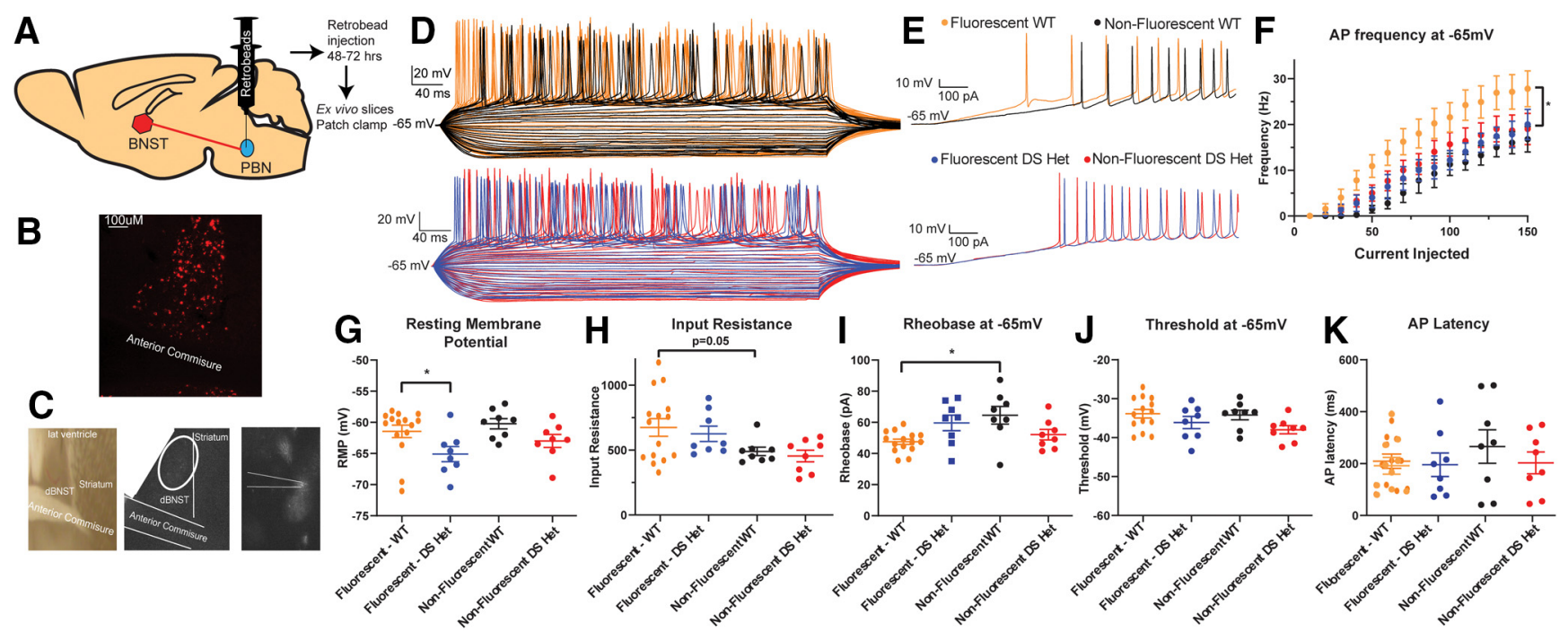

Figure 6. Neurons projecting from the dBNST to PBN are more excitable in WT mice and exhibit hypoexcitability in DS mice. $\boldsymbol{A}$, Schematic showing unilateral Retrobead injection into PBN. B, Representative image of fluorescent neurons in dBNST following Retrobead injection. $\boldsymbol{C}$, Representative image of fluorescent neurons being identified for patch clamp. $\boldsymbol{D}$, Representative traces of action potentials during current injection protocol in WT fluorescent neurons (top, orange), WT nonfluorescent (black), DS fluorescent (bottom, blue), and DS nonfluorescent (red). $\boldsymbol{E}$, Representative trace of ramp current injection in WT (top) and DS (bottom) mice. $\boldsymbol{F}$, Summary plot showing dBNST-to-PBN projection neurons in WT mice firing more action potentials and no change in DS neurons across a range of current injections (fluorescent WT, $n=15$; nonfluorescent WT, $n=8$; fluorescent DS, $n=8$; nonfluorescent DS, $n=8 ; p<0.0001$, two-way ANOVA). G, Scatter plot showing significant decrease in resting membrane potential of dBNST-toPBN projection neurons in DS mice compared with WT mice $(p=0.013)$. $\boldsymbol{H}$, Scatter plot showing a trend for increase in membrane resistance in PBN projecting neurons compared with other neurons in WT mice $(p=0.058)$. I, Scatter plot showing a significant decrease in rheobase in fluorescent neurons compared with nonfluorescent neurons in WT mice $(p=0.009)$. $\boldsymbol{J}, \boldsymbol{K}$, Scatter plots showing no significant changes in threshold and AP latency. ${ }^{*} p<0.05$.

regions in DS models, inhibitory neurons, particularly $\mathrm{PV}$ interneurons, have greatly diminished excitability and changes to AP kinetics. This was not seen overall in the BNST, likely because of the very small to nonexistent population of PV interneurons in this nucleus, as previously reported (Nguyen et al., 2016) and confirmed (Extended Data Fig. 5-1), which was unlikely to be sufficiently sampled by blind patching.

\section{Decreased excitability in BNST to PBN projection neurons}

We were interested in how any changes in the BNST excitability could alter autonomic functioning, breathing, and homeostatic behaviors that are perturbed in DS, so we evaluated dBNST neurons that project to the lateral PBN by using a retrograde tracing approach. We found that these projection neurons are a more excitable population compared with the dBNST as a whole, with a higher input resistance, a lower rheobase, a lower latency to fire APs, and a higher frequency of firing APs with each current injection. These attributes are no longer present in PBN-projecting neurons in DS mice, where these neurons also show a significant hyperpolarizing change in resting membrane potential, implying potential changes in potassium channel currents. These changes may be compensatory and driven by the aforementioned E-I balance increase, or by the epilepsy state itself. Potentially, GABAergic projection neurons to the PBN may have reduced excitability because of the loss of $\mathrm{Na}_{\mathrm{V}} 1.1$ channels
(Kalume et al., 2007); however, this seems less likely given the low basal level of Scn1a expression (Extended Data Fig. 5-1). These projection neurons may be preferentially bombarded by repeated cortical seizures, producing changes in intrinsic excitability to counteract this effect and overall diminishing output to the PBN.

\section{Functional implications}

The BNST is a limbic structure implicated in mediating behavioral responses to anxiety and stress, and is intimately interconnected to the larger amygdala circuit, hippocampus, and cortical regions (Lebow and Chen, 2016; Knight and Depue, 2019). The BNST may function as an integrator of these higher-order inputs, affecting its function over the autonomic nervous system, breathing, stress response, and homeostasis through dense projections to hypothalamic, midbrain, and brainstem nuclei, including the periventricular nucleus, ventral tegmental area, periaqueductal gray, nucleus tractus solitarius, PBN, and serotonergic neurons in the dorsal and midbrain raphe (Cassell et al., 1999; Dong and Swanson, 2004, 2006; Pollak Dorocic et al., 2014). In particular, there is evidence that the extended amygdala region may be critically involved in the respiratory dysfunction seen during seizures in DS (Kim et al., 2018; Kuo et al., 2019). Electrical stimulation of the human amygdala reliably produces apneas (Dlouhy et al., 2015; Lacuey et al., 2019; Nobis et al., $2018,2019)$. This is likely related to the stimulation of structures of the extended amygdala rather than the 
lateral regions (Nobis et al., 2018; Rhone et al., 2020). Similarly, seizure spread to these regions may be driving ictal apneas (Dlouhy et al., 2015; Nobis et al., 2019). The involvement of the extended amygdalar regions ( $\mathrm{CeA}$ and BNST) in ictal apneas may explain why the amygdala at large does not always produce apneas when activated by seizures (Park et al., 2020). The PBN has a known role in the modulation of breathing (Dutschmann and Herbert, 2006; Navarrete-Opazo et al., 2020) and has been targeted to rescue respiratory dysfunction in developmental disorders (Abdala et al., 2016). The BNST input to the PBN can influence respiration (Kim et al., 2013), so it is possible that the decreased intrinsic excitability of BNST projection neurons may produce compensatory changes in the PBN that allow strong stimuli in the form of a seizure to now produce an aberrant response, resulting in apneas. This could work in concert with dysfunction in other brainstem respiratory regions such as the retrotrapezoid nucleus (Kuo et al., 2019), which is more involved in setting respiratory rhythm (Guyenet et al., 2019), with disastrous outcomes leading to ictal breathing suppression and SUDEP. The known role of the lateral PBN in cardiovascular function may also be playing a role (Davern, 2014).

Outside of respiratory and cardiovascular function, the BNST inputs to the PBN have been implicated in anxiety, morphine withdrawal, feeding, and aversion (Mazzone et al., 2018; Luster et al., 2019; Wang et al., 2019). The PBN itself has important roles in other homeostatic functions including arousal and temperature regulation (Campos et al., 2018). Altered extended amygdalar inputs to this critical brainstem region could be driving some other persistent aspects of DS outside of seizures. This highlights the general need to explore subcortical structures in epilepsy models, in part to shed light on the comorbidities of epilepsy states. The few studies that have been performed evaluating these regions in human epilepsy patients show widespread alterations in subcortical network activity, including the brainstem, that correlate with impairments in vigilance and arousal (Englot et al., 2020). This current study emphasizes the need to evaluate these structures in DS and other epilepsy models, particularly in linking circuit dysfunction to other behavioral and physiologic comorbidities seen in epilepsy.

In sum, our results show that the BNST of the extended amygdala is activated in Scn1a ${ }^{+/-}$mice, and that there are neuroadaptations in this region in DS mice. These adaptations include decreased intrinsic excitability of those neurons projecting to the PBN in the brainstem. These alterations could potentially be driving comorbid aspects of DS outside of seizures, including respiratory dysfunction and sudden death.

\section{References}

Abdala AP, Toward MA, Dutschmann M, Bissonnette JM, Paton JFR (2016) Deficiency of GABAergic synaptic inhibition in the KöllikerFuse area underlies respiratory dysrhythmia in a mouse model of Rett syndrome. J Physiol 594:223-237.

Amakhin DV, Malkin SL, Ergina JL, Kryukov KA, Veniaminova EA, Zubareva OE, Zaitsev AV (2017) Alterations in properties of glutamatergic transmission in the temporal cortex and hippocampus following pilocarpine-induced acute seizures in Wistar rats. Front Cell Neurosci 11:264.

Bernard C (2015) Spreading depression: epilepsy's wave of death. Sci Transl Med 7:282fs14.

Bravo E, Marincovich A, Teran F, Crotts M, Lefkowitz RJ, Richerson G (2020) Postictal modulation of breathing by the central amygdala $(\mathrm{CeA})$ can induce sudden unexpected death in epilepsy (SUDEP). FASEB J 34:1-1.

Campos CA, Bowen AJ, Roman CW, Palmiter RD (2018) Encoding of danger by parabrachial CGRP neurons. Nature 555:617-622.

Cassell MD, Freedman LJ, Shi C (1999) The intrinsic organization of the central extended amygdala. Ann N Y Acad Sci 877:217-241.

Cheah CS, Frank HY, Westenbroek RE, Kalume FK, Oakley JC, Potter GB, Rubenstein JL, Catterall WA (2012) Specific deletion of NaV1. 1 sodium channels in inhibitory interneurons causes seizures and premature death in a mouse model of Dravet syndrome. Proc Natl Acad Sci U S A 109:14646-14651.

Ch'ng SS, Fu J, Brown RM, Smith CM, Hossain MA, McDougall SJ, Lawrence AJ (2019) Characterization of the relaxin family peptide 3 receptor system in the mouse bed nucleus of the stria terminalis. J Comp Neurol 527:2615-2633.

Davern PJ (2014) A role for the lateral parabrachial nucleus in cardiovascular function and fluid homeostasis. Front Physiol 5:436.

Derera ID, Delisle BP, Smith BN (2017) Functional neuroplasticity in the nucleus tractus solitarius and increased risk of sudden death in mice with acquired temporal lobe epilepsy. eNeuro 4: ENEURO.0319-17.2017.

Dlouhy BJ, Gehlbach BK, Kreple CJ, Kawasaki H, Oya H, Buzza C, Granner MA, Welsh MJ, Howard MA, Wemmie JA, Richerson GB (2015) Breathing inhibited when seizures spread to the amygdala and upon amygdala stimulation. J Neurosci 35:10281-10289.

Dong H-W, Swanson LW (2004) Organization of axonal projections from the anterolateral area of the bed nuclei of the stria terminalis. J Comp Neurol 468:277-298.

Dong H-W, Swanson LW (2006) Projections from bed nuclei of the stria terminalis, dorsomedial nucleus: implications for cerebral hemisphere integration of neuroendocrine, autonomic, and drinking responses. J Comp Neurol 494:75-107.

Dutschmann M, Herbert H (2006) The Kölliker-Fuse nucleus gates the postinspiratory phase of the respiratory cycle to control inspiratory off-switch and upper airway resistance in rat. Eur $\mathrm{J}$ Neurosci 24:1071-1084.

Dutton SBB, Dutt K, Papale LA, Helmers S, Goldin AL, Escayg A (2017) Early-life febrile seizures worsen adult phenotypes in Scn1a mutants. Exp Neurol 293:159-171.

Egli RE, Winder DG (2003) Dorsal and ventral distribution of excitable and synaptic properties of neurons of the bed nucleus of the stria terminalis. J Neurophysiol 90:405-414.

Englot DJ, Morgan VL, Chang C (2020) Impaired vigilance networks in temporal lobe epilepsy: mechanisms and clinical implications. Epilepsia 61:189-202.

Favero M, Sotuyo NP, Lopez E, Kearney JA, Goldberg EM (2018) A transient developmental window of fast-spiking interneuron dysfunction in a mouse model of Dravet syndrome. J Neurosci 38:7912-7927.

Fernandes HB, Catches JS, Petralia RS, Copits BA, Xu J, Russell TA, Swanson GT, Contractor A (2009) High-affinity kainate receptor subunits are necessary for ionotropic but not metabotropic signaling. Neuron 63:818-829.

Gataullina S, Dulac O (2017) From genotype to phenotype in Dravet disease. Seizure 44:58-64.

Guyenet PG, Stornetta RL, Souza GMPR, Abbott SBG, Shi Y, Bayliss DA (2019) The retrotrapezoid nucleus: central chemoreceptor and regulator of breathing automaticity. Trends Neurosci 42:807-824.

Hammack SE, Mania I, Rainnie DG (2007) Differential expression of intrinsic membrane currents in defined cell types of the anterolateral bed nucleus of the stria terminalis. J Neurophysiol 98:638656. 
Hedrick TP, Nobis WP, Foote KM, Ishii T, Chetkovich DM, Swanson GT (2017) Excitatory synaptic input to hilar mossy cells under basal and hyperexcitable conditions. eNeuro 4:ENEURO.036417.2017.

Hsieh PF, Watanabe Y (2000) Time course of c-FOS expression in status epilepticus induced by amygdaloid stimulation. Neuroreport 11:571574.

Huffman AM, Calhoun J, Kearney J (2018) Activity mapping of seizures in a mouse model of Dravet syndrome. FASEB J 32:556.4.

Isom LL (2014) "It was the interneuron with the parvalbumin in the hippocampus!" "No, it was the pyramidal cell with the glutamate in the cortex!" Searching for clues to the mechanism of Dravet syndrome-the plot thickens: Dravet syndrome-it's not only interneurons. Epilepsy Curr 14:350-352.

Kalume F, Yu FH, Westenbroek RE, Scheuer T, Catterall WA (2007) Reduced sodium current in Purkinje neurons from $\mathrm{Na}_{\mathrm{v}} 1.1$ mutant mice: implications for ataxia in severe myoclonic epilepsy in infancy. J Neurosci 27:11065-11074.

Kalume F, Westenbroek RE, Cheah CS, Yu FH, Oakley JC, Scheuer T, Catterall WA (2013) Sudden unexpected death in a mouse model of Dravet syndrome. J Clin Invest 123:1798-1808.

Kim S-Y, Adhikari A, Lee SY, Marshel JH, Kim CK, Mallory CS, Lo M, Pak S, Mattis J, Lim BK, Malenka RC, Warden MR, Neve R, Tye KM, Deisseroth K (2013) Diverging neural pathways assemble a behavioural state from separable features in anxiety. Nature 496:219-223.

Kim Y, Bravo E, Thirnbeck CK, Smith-Mellecker LA, Kim SH, Gehlbach BK, Laux LC, Zhou X, Nordli DR Jr, Richerson GB (2018) Severe peri-ictal respiratory dysfunction is common in Dravet syndrome. J Clin Invest 128:1141-1153.

Knight LK, Depue BE (2019) New frontiers in anxiety research: the translational potential of the bed nucleus of the stria terminalis. Front Psychiatry 10:510.

Kuo F-S, Cleary CM, LoTurco JJ, Chen X, Mulkey DK (2019) Disordered breathing in a mouse model of Dravet syndrome. Elife 8:e43387.

Lacuey N, Hampson JP, Harper RM, Miller JP, Lhatoo S (2019) Limbic and paralimbic structures driving ictal central apnea. Neurology 92:e655-e669.

Lebow MA, Chen A (2016) Overshadowed by the amygdala: the bed nucleus of the stria terminalis emerges as key to psychiatric disorders. Mol Psychiatry 21:450-463.

Li C, Pleil KE, Stamatakis AM, Busan S, Vong L, Lowell BB, Stuber GD, Kash TL (2012) Presynaptic inhibition of gamma-aminobutyric acid release in the bed nucleus of the stria terminalis by kappa opioid receptor signaling. Biol Psychiatry 71:725-732.

Lopez-Santiago L, Isom LL (2019) Dravet syndrome: a developmental and epileptic encephalopathy. Epilepsy Curr 19:51-53.

Luster BR, Cogan ES, Schmidt KT, Pati D, Pina MM, Dange K, McElligott ZA (2019) Inhibitory transmission in the bed nucleus of the stria terminalis in male and female mice following morphine withdrawal. Addict Biol 25:e12748.

Mazzone CM, Pati D, Michaelides M, DiBerto J, Fox JH, Tipton G, Anderson C, Duffy K, McKlveen JM, Hardaway JA, Magness ST, Falls WA, Hammack SE, McElligott ZA, Hurd YL, Kash TL (2018) Metabolic mapping of downstream network activity following CNO-induced activation of hM3Dq in BNST VGAT neurons. Mol Psychiatry 23:1.

Miller AR, Hawkins NA, McCollom CE, Kearney JA (2014) Mapping genetic modifiers of survival in a mouse model of Dravet syndrome. Genes Brain Behav 13:163-172.

Misra C, Brickley SG, Farrant M, Cull-Candy SG (2000) Identification of subunits contributing to synaptic and extrasynaptic NMDA receptors in Golgi cells of the rat cerebellum. J Physiol 524:147-162.

Mistry AM, Thompson $\mathrm{CH}$, Miller AR, Vanoye CG, George AL Jr, Kearney JA (2014) Strain- and age-dependent hippocampal neuron sodium currents correlate with epilepsy severity in Dravet syndrome mice. Neurobiol Dis 65:1-11.
Navarrete-Opazo AA, Cook-Snyder DR, Miller JR, Callison JJ, McCarthy N, Palkovic B, Stuth EAE, Zuperku EJ, Stucke AG (2020) Endogenous glutamatergic inputs to the parabrachial nucleus/ Kölliker-Fuse complex determine respiratory rate. Respir Physiol Neurobiol 277:103401.

Nguyen AQ, Dela Cruz JAD, Sun Y, Holmes TC, Xu X (2016) Genetic cell targeting uncovers specific neuronal types and distinct subregions in the bed nucleus of the stria terminalis. J Comp Neurol 524:2379-2399.

Nobis WP, Schuele S, Templer JW, Zhou G, Lane G, Rosenow JM, Zelano C (2018) Amygdala-stimulation-induced apnea is attention and nasal-breathing dependent. Ann Neurol 83:460-471.

Nobis WP, González Otárula KA, Templer JW, Gerard EE, VanHaerents S, Lane G, Zhou G, Rosenow JM, Zelano C, Schuele S (2019) The effect of seizure spread to the amygdala on respiration and onset of ictal central apnea. J Neurosurg 132:1313-1323.

Park K, Kanth K, Bajwa S, Girgis F, Shahlaie K, Seyal M (2020) Seizure-related apneas have an inconsistent linkage to amygdala seizure spread. Epilepsia 61:1253-1260.

Paxinos G, Franklin KBJ (2019) Paxinos and Franklin's the mouse brain in stereotaxic coordinates. London: Academic.

Perrotti LI, Hadeishi Y, Ulery PG, Barrot M, Monteggia L, Duman RS, Nestler EJ (2004) Induction of $\triangle F$ FosB in reward-related brain structures after chronic stress. J Neurosci 24:10594-10602.

Pollak Dorocic I, Fürth D, Xuan Y, Johansson Y, Pozzi L, Silberberg G, Carlén M, Meletis K (2014) A whole-brain atlas of inputs to serotonergic neurons of the dorsal and median raphe nuclei. Neuron 83:663-678.

Regehr WG (2012) Short-term presynaptic plasticity. Cold Spring Harb Perspect Biol 4:a005702.

Reichard RA, Subramanian S, Desta MT, Sura T, Becker ML, Ghobadi CW, Parsley KP, Zahm DS (2017) Abundant collateralization of temporal lobe projections to the accumbens, bed nucleus of stria terminalis, central amygdala and lateral septum. Brain Struct Funct 222:1971-1988.

Rhone AE, Kovach CK, Harmata GI, Sullivan AW, Tranel D, Ciliberto MA, Howard MA, Richerson GB, Steinschneider M, Wemmie JA, Dlouhy BJ (2020) A human amygdala site that inhibits respiration and elicits apnea in pediatric epilepsy. $\mathrm{JCl}$ Insight 5:e134852.

Rodríguez-Sierra OE, Turesson HK, Pare D (2013) Contrasting distribution of physiological cell types in different regions of the bed nucleus of the stria terminalis. J Neurophysiol 110:2037-2049.

Silberman Y, Matthews RT, Winder DG (2013) A corticotropin releasing factor pathway for ethanol regulation of the ventral tegmental area in the bed nucleus of the stria terminalis. J Neurosci 33:950960.

Tai C, Abe Y, Westenbroek RE, Scheuer T, Catterall WA (2014) Impaired excitability of somatostatin- and parvalbumin-expressing cortical interneurons in a mouse model of Dravet syndrome. Proc Natl Acad Sci U S A 111:E3139-48.

Tsai M-S, Lee M-L, Chang C-Y, Fan H-H, Yu I-S, Chen Y-T, You $\mathrm{J}-\mathrm{Y}$, Chen $\mathrm{C}-\mathrm{Y}$, Chang F-C, Hsiao JH, Khorkova O, Liou H-H, Yanagawa Y, Lee L-J, Lin S-W (2015) Functional and structural deficits of the dentate gyrus network coincide with emerging spontaneous seizures in an Scn1a mutant Dravet Syndrome model during development. Neurobiol Dis 77:35-48.

Villas N, Meskis MA, Goodliffe S (2017) Dravet syndrome: characteristics, comorbidities, and caregiver concerns. Epilepsy Behav 74:81-86.

Wang L, Shen M, Jiang C, Ma L, Wang F (2016) Parvalbumin interneurons of central amygdala regulate the negative affective states and the expression of corticotrophin-releasing hormone during morphine withdrawal. Int J Neuropsychopharmacol 19: pyw060.

Wang Y, Kim J, Schmit MB, Cho TS, Fang C, Cai H (2019) A bed nucleus of stria terminalis microcircuit regulating inflammation-associated modulation of feeding. Nat Commun 10:2769. 
Wyeth MS, Pelkey KA, Petralia RS, Salter MW, McInnes RR, McBain CJ (2014) Neto auxiliary protein interactions regulate kainate and NMDA receptor subunit localization at mossy fiber-CA3 pyramidal cell synapses. J Neurosci 34:622-628.

Yu FH, Mantegazza M, Westenbroek RE, Robbins CA, Kalume F, Burton KA, Spain WJ, McKnight GS, Scheuer T, Catterall WA
(2006) Reduced sodium current in GABAergic interneurons in a mouse model of severe myoclonic epilepsy in infancy. Nat Neurosci 9:1142-1149.

Yuan Y, O'Malley HA, Smaldino MA, Bouza AA, Hull JM, Isom LL (2019) Delayed maturation of GABAergic signaling in the Scn1a and Scn1b mouse models of Dravet syndrome. Sci Rep 9:6210. 